\author{
Pathophysiology \\ of Haemostasis \\ and Thrombosis
}

\title{
The Mediterranean Lecture: Wine and Thrombosis - From Epidemiology to Physiology and Back
}

\author{
Giovanni de Gaetano, Augusto Di Castelnuovo, Maria B. Donati, Licia \\ lacoviello
}

Research Laboratories, Center for High Technology Research and Education in Biomedical Sciences, Catholic University Campobasso, Italy

\section{Key Words \\ Alcohol - Wine - Cardiovascular risk - Polyphenols · Mediterranean diet}

\begin{abstract}
The protective effect of moderate alcohol consumption on the risk of cardiovascular disease has been consistently shown in many epidemiological studies. Antiatherogenic alterations in plasma lipoproteins, particularly increase in high-density lipoprotein (HDL) cholesterol, are considered as the most plausible mechanism of the protective effect of alcohol consumption on coronary artery disease (CHD). Other potential mechanisms contributing to the cardio-protective effects of moderate alcohol consumption include anti-thrombotic down regulation of blood platelet function, as well as of the coagulation and fibrinolysis balance. Since the proposal of a "French paradox" in the early Nineties, the possibility that consuming alcohol in the form of wine might confer a protection against CHD above that expected from its alcohol content, has made the topic "wine and health" increasingly popular. Many epidemiological studies have explored such a possibility, by comparing specific alcoholic beverage types (wine, beer, liqueur) in respect to their relative capacity to reduce the risk of CHD. In parallel, experimental stud-
\end{abstract}

\section{KARGER}

Fax +41613061234

E-Mail: karger@karger.ch

www.karger.com
(C) 2004 S. Karger AG, Basel

1424-8832/04/0336-0466\$21.0/0

Accessible online at: www.krager.com/pht ies have been done, in which wine and wine-derived products have been tested for their capacity to interfere with molecular and cellular mechanisms relevant to the pathogenesis of CHD. Wine might indeed conceivably have other ethanol unrelated beneficial effects. The biological rationale for such a hypothesis has been linked to the enrichment in grape-derived, non-alcoholic components, that possibly make it peculiar in respect to other alcoholic beverages. In fact, while the mechanisms underlying the effects of alcohol on cardiovascular disease have been limited to lipid metabolism and the haemostatic system, those related to wine consumption have also been extended to specific anti-inflammatory, antioxidant and nitric oxiderelated vaso-relaxant properties of its polyphenolic constituents. The effect of wine consumption has been carefully investigated to account for potential confounding of several conditions (inappropriate use of abstainers as control population, correlation between wine or total alcohol consumption and markers of healthy lifestyle and socioeconomic factors, diet, etc.). Strong evidence indicates that moderate wine consumption rather than confounders reduces both fatal and non fatal CHD events. In spite of the fact that the healthy effect of moderate intake of wine is by now well accepted, important issues remain to be resolved about the relationship between wine, alcohol and

Giovanni de Gaetano, M.D., Ph.D.

Head, Research Laboratories

Center for High Technology Research, and Education in Biomedical Sciences

Catholic University

86100 Campobasso, Italy

Tel +39 0874312 280; Fax +390874 312 710; E-mail: gdegaetano@rm.unicatt.it 
CHD. Among these are the differences in types of alcoholic beverages, the (possibly different) optimal amount of alcohol intake in men and women, the individual or environmental modulation of the alcoholrelated effect and the pattern of drinking. Some of these issues have been recently addressed in a large meta-analysis, in which the relationship between wine or beer consumption and CHD risk was quantitatively evaluated. We shall summarize here the experimental and epidemiological studies with wine or wine-derived products aimed at finding biological explanations for the supposed superior cardio-protective effects of wine consumption and to discuss some open questions about wine and vascular disease as approached in epidemiological studies.

Copyright (c) 2004 S. Karger AG, Basel

\section{Introduction}

Light to moderate drinkers of alcohol are at lower risk of vascular disease and death than non-drinkers [1-10]. The protective effect of moderate assumption of ethanol has been linked to anti-atherogenic alterations in plasma lipoproteins, as well as to anti-thrombotic modifications of blood platelet function, as well as of the coagulation and fibrinolysis balance [11]. The assumption of ethanol in the form of wine might conceivably have other non-ethanol related beneficial effects, linked to specific antioxidant and vaso-relaxant properties of its polyphenolic constituents [12].

We shall summarize here below experimental and epidemiological data supporting the cardio-protective effects of moderate wine intake.

\section{Evidence from Experimental Studies}

\section{Anti-Atherogenic Effects}

Alterations in plasma lipoproteins were considered as the most plausible mechanism of the protective effect of wine consumption on coronary artery disease (CHD) [13]. The antioxidant properties of polyphenols (grape-derived components of wine) may delay the onset of atherogenesis by reducing chemically mediated peroxidative reactions [14]. The potential in vivo antioxidant properties of wine have therefore been evaluated in terms of their ability to enhance plasma antioxidant status as well as to reduce specific oxidative processes. Studies in volunteers showed increased plasma antioxidant capacity or protection of LDL from oxidation after consumption of red wine [15-16]. A marked suppression of plasma post-prandial hydroperoxide increase was found in volunteers when a fatty meal was consumed with wine, instead of water [17]. Other relevant antiatherogenic modifications concern the reported ability of red wine to increase plasma levels of HDL at levels above that obtained after alcohol consumption [12], or to reduce lipid deposition, in animal models, independently of their effects on lipid peroxidation [18]. As inflammation is a crucial component of the atherosclerotic process, it is of interest that resveratrol, a wine-derived polyphenol, significantly reduced the degree of colon injury, neutrophil infiltration, the levels cytokines and the COX-2 expression in an animal model of experimentally induced colitis (19).

\section{Anti-thrombotic Effects}

Other potential mechanisms contributing to the cardioprotective effect of moderate alcohol consumption include alterations of blood platelet function, coagulation and fibrinolysis. Alcohol seems to affect several factors involved in maintaining the delicate equilibrium between clot formation to protect against bleeding and clot dissolution to prevent blood clots from forming in arteries, and which have been implicated as risk factors for myocardial infarction [11].

Alcohol consumption has been associated with increased levels of tissue plasminogen activator (tPA), lower levels of fibrinogen and antithrombin III [20-22], and reduced platelet susceptibility to aggregation [23,24].

Polyphenols interfere with arachidonic acid metabolism, resulting in inhibition of platelet aggregation and reduced synthesis of pro-thrombotic and pro-inflammatory mediators [25-27]. Polyphenols can also down-regulate the expression of adhesive molecules and tissue factor activity, resulting in functional modulation of cell-cell interactions and procoagulant activities [26,28]. Tissue factor activity induced by any agonist was significantly reduced by resveratrol or quercetin [29-31]. Wine polyphenols were also shown to modulate nitric oxide (NO)-mediated responses. Fitzpatrick et al. [32] first showed that certain wine extracts were able to relax pre-contracted smooth muscle of intact aortic ring, and Andriambeloson et al. [33] demonstrated that the endothelium-dependent vaso-relaxation of rat aorta was mediated by an increase of NO aortic content. In addition, incubation of endothelial cells with red wines up regulated NO synthase mRNA and protein expression, and produced up to three times more bioactive NO than did control cells [34]. Martin et al. [35] showed that both delphinidin and anthocyanidin (two polyphenols from red wine), inhibit endothelial cell apoptosis via NO pathway and regulation of calcium homeostasis. Wine itself may ameliorate endothelial dysfunction. In healthy volunteers acute smoking caused a reduction in flow-mediated dilatation (FMD), but simultaneous ingestion of either red wine or de-alco-

Pathophysiol Haemost Thromb 2003/2004;33:466-471 
holized red wine with smoking prevented such a change in FMD, suggesting that wine can decrease smoke's harmful effect on endothelium [39]. Wine acutely improves endothelial function, measured as FMD, also in patients with coronary artery disease, although there was no detectable change in plasma polyphenol levels after wine consumption.

Platelet adhesion to damaged endothelium and subsequent platelet aggregation are major steps in both thrombosis and atherogenesis. Several studies have evaluated the possibility that alcohol consumption in the form of wine might have effect on human platelet function, additive to those already known to be exerted by alcohol. However, the antiplatelet activity of wine polyphenols observed in vitro [36, 37] and in experimental animal models [38], seems not to confer significant benefit, above that offered by alcohol itself, in human studies.

\section{A European Collaboration on "Wine and Cardiovascular Disease"}

The E.U.-supported FAIR Program included a collaborative project among several European partners aimed at evaluating the effects of red wine polyphenolic extracts (RWPE) on vascular tone, haemostatic system, oxidative processes, and plaque development [41]. Evidence was obtained that RWPE might improve vascular function mainly through NO-mediated mechanisms, interfere with haemostatic and oxidative processes involved in the progression of vascular damage, and modulate early events of atherosclerosis. A study in healthy Spanish volunteers showed a significant increase in HDL cholesterol levels and a decreased oxidation of LDL after moderate red wine ingestion (30 g daily for one month) as compared to the same amount of alcohol given as polyphenol-poor spirit [41]. A significant increase in HDL cholesterol levels and a decreased oxidation of LDL was observed both after red wine and gin ingestion (Table 1). A significant fall was seen, after red wine only, in the expression of several markers of cardiovascular risk, including the activity of MAC-1 and other adhesion molecules [42]. In the same group of volunteers it was found that TNF-alpha -induced adhesion of monocytes to endothelial cells was virtually abolished after wine consumption, but only partially reduced after gin [43] Thus ethanol itself has potential beneficial effects on the cardiovascular system, mainly increasing HDL-cholesterol and decreasing oxidation of LDL. Wine may give additional benefits due to its greater antioxidant and anti-inflammatory effects.

\section{Wine and the Mediterranean diet}

Besides red wine, important sources of polyphenols are other beverages, foods and fruits. The source of different polyphenols may therefore vary in different populations [44]. On the other hand, the advantages of certain dietary
Table 1. Schematic effect of polyphenol-poor gin or red wine intake on different biochemical parameters in healthy subjects

Parameter measured

modified from reference 41 , with permission

habits with respect to the risk oh CHD, have been extensively shown [45, 46]. High consumption of cereals, legumes, vegetables, and fruits, low consumption of red meat and dairy products, and the traditional use of olive oil, are the main characteristics of what is now considered as the healthy Mediterranean diet [47]. The observed correlation between wine and other foodstuffs such as fish and fruit and CHD mortality, suggest that the maintenance of traditionally Mediterranean lifestyle habits may contribute to decline in CHD mortality $[47,48]$. Wine is the beverage of choice for Mediterranean populations and although it is not considered to be per se a component of the Mediterranean diet, its regular and moderate consumption may contribute to the lower rates of fatal and non fatal CHD observed in these populations [47].

\section{Evidence from Epidemiological Studies}

An inverse association between moderate alcohol consumption and CHD has been consistently shown in many epidemiological studies [1-10], but important issues remain to be clarified.

\section{Differences among Different Alcoholic Beverages}

Specific alcoholic beverages may have a different benefit. Renaud and de Lorgeril suggested wine intake as one possible explanation for the lower than expected CHD mor-

de Gaetano/Di Castelnuovo/Donati/Iacoviello 


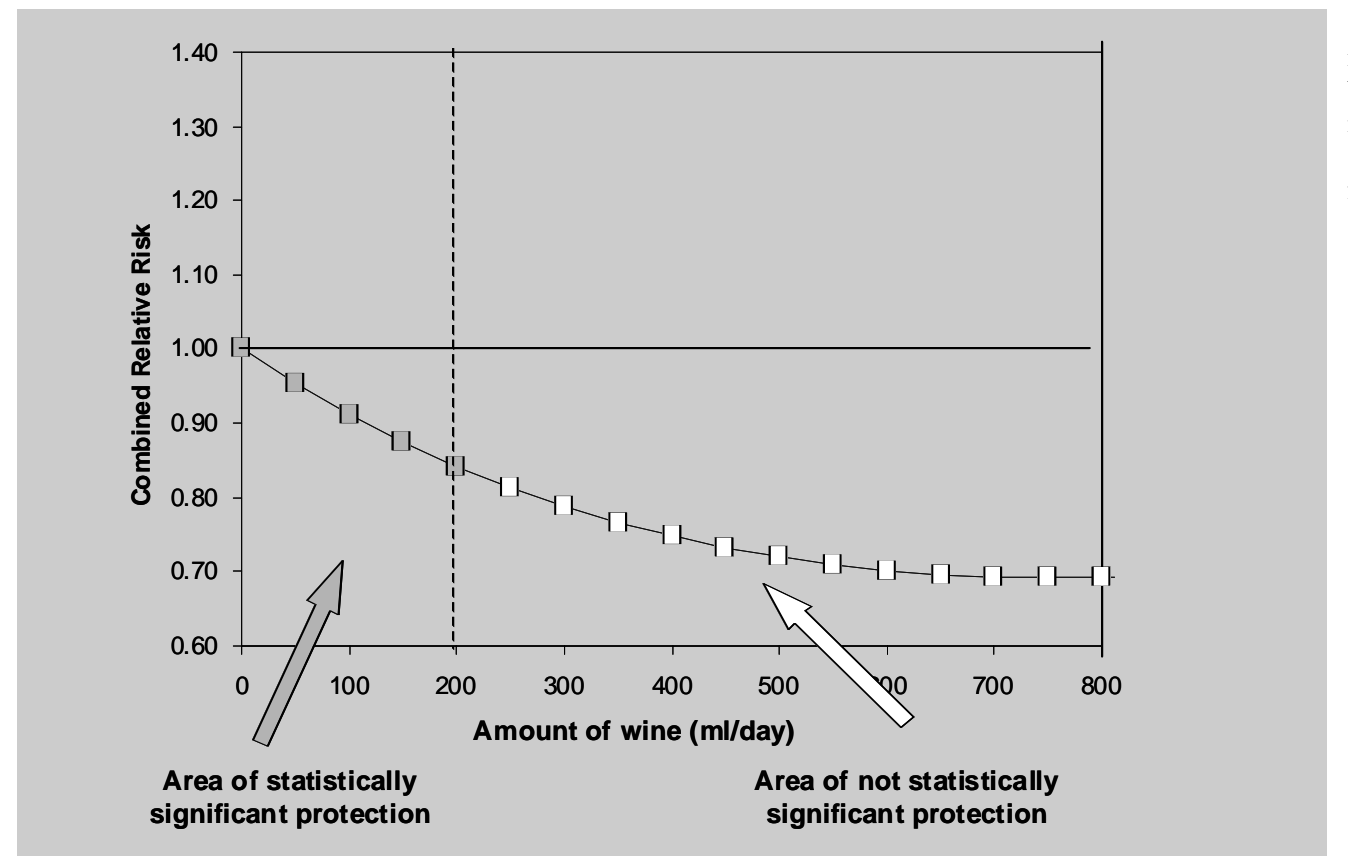

Fig. 1. Dose-response best fitting model for wine effect against combined vascular risk, obtained pooling "dose-response" curves in seven prospective studies (adapted from ref. 6, with permission)

tality rates in France (the "French Paradox") [7], and many subsequent epidemiological studies have explored the French-paradox-generated hypothesis. We reviewed such studies in two meta-analyses based on 26 articles (including more than 200,000 persons) reporting comparisons between wine and beer and the risk of CHD [1]. The overall relative risk (RR) of wine drinkers in respect to non drinkers was 0.68 (95\% confidence interval (95\% CI): 0.59-0.77), whereas the protection associated with beer drinking was $10 \%$ lower (in absolute terms). In studies reporting dose-response curves, a clear non-linear dose-response curve was found between wine and vascular risk (Figure 1), but we failed to show any significant relationship between different amounts of beer intake and vascular risk. After the publication of our meta-analyses, three additional articles have been published. In the last report from the Framingham Study [8] about alcohol consumption and ischemic stroke, wine (but not beer or spirits) was related to a decreased risk of ischemic stroke ( $\mathrm{RR}=0.8$; 95\%CI: 0.6 to 1.0$)$. In a report [10] on mortality and alcohol consumption in a very large USA cohort (128 934 adults, 16431 deaths in 20 years of follow up), protective effect of moderate alcohol intake against cardiovascular deaths was essentially restricted to women (20\% reduced risk versus a non significant $10 \%$ reduction in men) that were more likely to drink wine. In contrast, the association of different types of alcoholic beverages with CHD risk evaluated in 38077 USA males was strongest for beer and liquor, and weakest for wine [5].

\section{Is there an Optimal Amount of Wine?}

The dose-response relationship between alcohol intake and rate of CHD has been traditionally depicted as a Jshaped curve [3], which means that non drinkers have higher risks than moderate drinkers, but similar or lower rates than heavy drinkers. In our meta-analysis [1] we confirmed the "J-shaped" curve since, after an initial decrease in the vascular risk by increasing amounts of wine, the curve reaches a plateau at higher intake, and tends to be reverted at the highest amounts explored (Figure 1). A maximum reduction was predicted at $750 \mathrm{ml} /$ day, but statistical significance was only reached up to the amount of 150-200 $\mathrm{ml} /$ day, indicating that the amount of wine for which the balance between risk and benefit is the best in favor of wine is in the range 1 to 2 drinks a day, in agreement with international guidelines [49].

\section{Differences According to Clinical Phenotypes}

In subgroup analysis according to type of events, we found comparable protective effects of wine [1]. Wine intake was associated, indeed, with a decrease of both CHD $(R R=0.71)$ and cerebrovascular disease $(R R=0.43)$, and with both nonfatal $(R R=0.71)$ and fatal vascular events $(\mathrm{RR}=0.49)$ (Table 1$)$. Wine consumption was not significantly associated with myocardial infarction in the Health Professional Follow-Up Study [5] but it was so with ischemic stroke in Framingham Study [8]. The impressive study of Klatsky et al. [10] confirm the protective role of wine against total mortality. Quite recently, de Lorgeril et al [4] found a positive association of moderate wine intake with recurrences in survivors of a recent myocardial infarc-

Pathophysiol Haemost Thromb 2003/2004;33:466-471 
tion, suggesting that moderate alcohol (wine) consumption may have positive effect in secondary prevention too.

\section{A Sex-related Effect of Wine?}

In our meta-analysis [1] we found that in studies enrolling only males, the protection offered by wine was small (13\%) and not significant, in contrast with studies enrolling both genders (47\% protection). In the Health Professional Follow-Up Study [5] conducted on USA males, the effect of wine was also small and not significant. An ad hoc analysis of the two USA studies included in our metaanalysis [1] where only males had been enrolled, showed no protective effect of wine. However in the five studies conducted in USA, but enrolling both sexes, overall relative risk reduction in favor of wine drinkers was 0.46 [2].

In the study of Klastky et al. [10] too the protection appeared to be confined to women. Thus, a possible sex difference in the protective effect of wine on vascular risk might exist and explain apparently controversial results in different epidemiological studies. However, in a metaanalysis of 12 studies comparing alcohol consumption (without any specific beverage distinction) in groups of males or females, we have lately failed to evidentiate any significant sex difference in the reduction of cardiovascular risk [50]. It is tempting to speculate that wine but not alcohol might exert a sex-related protection against cardio-vascular disease, but either experimental or clinical support to this hypothesis is still lacking. As a last comment in relation to the reported association between moderate alcohol consumption and increased risk of breast cancer [51], evidence suggests that the overall effect of moderate wine intake on women health may actually be favorable.

\section{Genetic Regulation of Alcohol Effects}

A strong interaction between alcohol intake and a common polymorphism in the gene for alcohol de-hydrogenase [52] has been observed; this finding supports causality of the health effect of ethanol, because such a result cannot plausi- bly be attributed to confounding factors. Future studies should investigate if a gene-regulation specifically for the effect of wine does exist. Differences in the ethnic distribution of alcohol or wine related polymorphisms might explain controversial results in different epidemiological studies.

\section{Conclusions}

Some cardio-protective effect of most alcoholic beverages is probably due to ethanol-induced elevation of HDL and lowering of platelet aggregation, but the cardio-protective effect of (red) wine may be attributed at least in part to the antioxidant, vaso-relaxant and anti-thrombotic properties of naturally occurring (polyphenolic) compounds in wine.

Strong epidemiological evidence indicates that moderate (1-2 drinks a day) consumption of wine is associated with a significant reduction of vascular events. It is controversial whether definite proof could be obtained by large long-term intervention trials [53].

In a public health perspective, wine and alcohol should be avoided whenever consumption would put an individual or others at risk, such as during pregnancy or before driving. We must avoid that the lives that are saved by preventing heart attacks, are subsequently lost because of liver or other disease such as hypertension or tumors. In conclusion, besides insisting on the control of risk factors, abstainers should be informed that, in the absence of contraindications and in the context of healthy eating and lifestyle, low-moderate wine consumption may contribute to a better health. People who are already regular light-moderate wine consumers should be encouraged to continue. The hazards of excess drinking should be always highlighted, and heavy drinkers pushed to cut their consumption to a moderate level [1].

\section{References}

1 Di Castelnuovo A, Rotondo S, Iacoviello L, Donati MB, de Gaetano G. Circulation 2002;105:2836-2844.

2 Di Castelnuovo A, Iacoviello L, de Gaetano G. N Engl J Med 2003;348:1719-1722.

3 Corrao G, Rubbiati L, Bagnardi V, Zambon A, Poikolainen K. Addiction 2000;95:1505-1523.

4 de Lorgeril M, Salen P, Martin JL, Boucher F, Paillard F, de Leiris J. Circulation 2002 ;106:14651469.

5 Mukamal KJ, Conigrave KM, Mittleman MA, Camargo CA Jr, Stampfer MJ, Willett WC, Rimm EB. N Engl J Med 2003;348:109-118.
Reynolds K, Lewis B, Nolen JD, Kinney GL, Sathya B, He J. JAMA 2003;289:579-588.

Renaud S, De Lorgeril M. Lancet 1992;339:15231526.

8 Djousse L, Curtis Ellison R, Beiser A, Scaramucci A, D'Agostino RB, Wolf PA. Stroke 2002;33:907912.

9 Jackson VA, Sesso HD, Buring JE, Gaziano JM Arch Intern Med 2003;163:1189-1193

10 Klatsky AL, Friedman GD, Armstrong MA, Kipp H. Am J Epidemiol. 2003;158:585-95.

11 Rimm EB, Williams P, Fosher K, Criqui M, Stampfer MJ. BMJ 1999;319: 1523-1528.

12 de Gaetano G, De Curtis A, Di Castelnuovo A. Ann N Y Acad Sci 2002;957:174-188.
Higdon JV, Frei B. Crit Rev Food Sci Nutr 2003;43:89-143.

14 Rice-Evans C, Miller NJ, Paganga G. Trends Plant Sci 1997;2:152-159.

15 Serafini M, Maiani G, Ferro-Luzzi A. J Nutr 1998;128:1003-1007.

16 Cao G, Russell RM, Lischner N, Prior RL. J Nutr $1998 ; 128: 2383-2390$

17 Ursini F, Zamburlini A, Cazzolato G, Maiorino M Sevanian A. Free Radic Biol Med 1998 ;25:250252.

18 Waddington E, Puddey IB, Croft KD. Am J Clin Nutr. 2004;791:54-61.

19 Martin AR, Villegas I, La Casa C, de la Lastra CA. Biochem Pharmacol. 2004;67:1399-1410.

de Gaetano/Di Castelnuovo/Donati/Lacoviello 
20 Ridker PM, Vaughan DE, Stampfer MJ, Glynn RJ, Hennekens CH. JAMA 1994;272:929-933.

21 Bijnen FC, Feskens EJ, Giampaoli S, Menotti A, Fidanza F, Hornstra G, Caspersen CJ, Mosterd WL, Kromhout D. Thromb Haemost 1996;76:411416.

22 Woodward M, Lowe GDO, Rumley A, TunstallPedoe H, Philippou H, Lane DA, Morrison CE. Br J Haematol 1997;97:785-797.

23 Elwood PC, Beswick AD, O'Brien JR, Yarnell JWG, Layzell JC, Limb ES. Blood Coagul Fibrinolysis 1993;4:529-536.

24 Renaud SC, Ruf JC. Clin Chim Acta 1996;246:7789.

25 Pace-Asciak CR, Rounova O, Hahn SE, Diamandis EP, Goldberg DM. Clin Chem 1996;246:163-182.

26 Rotondo S, Rajtar G, Manarini S, Celardo A, Rotilio D, de Gaetano G, Evangelista V, Cerletti C. Br J Pharmacol 1998;123:1691-1699.

27 Polette A, Lemaitre D, Lagarde M, Véricel E. Thromb Haemost 1996;75:945-949.

28 Pendurthi UR, Williams JT, Rao LV. Arterioscler Thromb Vasc Biol 1999;19:419-426.

29 Pendurthi UR, Meng F, Mackman N, Rao LV. Thromb Haemost 2002;87:155-162.

30 Mu MM, Chakravortty D, Sugiyama T, Koide N, Takahashi K, Mori I, Yoshida T, Yokochi T. J Endotoxin Res 2001;7:431-438.

31 Di Santo A, Mezzetti A, Napoleone E, Di Tommaso R, Donati MB, de Gaetano G, Lorenzet R.J Thromb Haemost 2003;1:1089-1095.

32 Fitzpatrick FA, Hirschfield SL, Coffey RG. Am J Physiol Heart Circ Physiol 1993;34,265:H774H778.
33 Andriambeloson E, Kleschyov AL, Muller B, Beretz A, Stoclet JC, Andriantsitohaina R. Br J Pharmacol 1997;120:1053-1058.

34 Wallerath T, Poleo D, Li H, Forstermann U. J Am Coll Cardiol 2003;41:471-478

35 Martin S, Giannone G, Andriantsitohaina R, Martinez MC. Br J Pharmacol 2003;139:10951102.

36 Pace-Asciak CR, Hahn S, Diamandis EP, Soleas G, Goldberg DM. Clin Chim Acta 1995;235:207-219

37 Rotondo S, Rotilio D, Cerletti C, de Gaetano G. Thromb Haemost 1996;76:818-819.

38 Wollny T, Aiello L, Di Tommaso D, Bellavia V, Rotilio D, Donati MB, de Gaetano G, Iacoviello L. Br J Pharmacol 1999;127:747-755.

39 Papamichael C, Karatzis E, Karatzi K, Aznaouridis K, Papaioannou T, Protogerou A, Stamatelopoulos K, Zampelas A, Lekakis J, Mavrikakis M. Am Heart J. 2004;147:E5.

40 Whelan AP, Sutherland WH, McCormick MP, Yeoman DJ, De Jong SA, Williams MJ. Intern Med J. 2004;34:224-228.

41 de Gaetano G and Cerletti C. Nutr Metab Cardiovasc Dis 2001:114 Suppl:47-50.

42 Estruch R, Sacanella E, Badia E, Antunez E, Nicolas JM, Fernandez-Sola J, Rotilio D, Rubin E, de Gaetano G, Urbano-Marquez A. Atherosclerosis 2004, in press.

43 Badia E, Sacanella E, Fernandez-Sola J, Nicolas JM, Antunez E, Rotilio D, de Gaetano G, UrbanoMarquez A, Estruch R. Am J Clin Nutrit. 2004, in press.

44 Contaldo F, Pasanisi F, Mancini M. Nutr Metab Cardiovasc Dis 2003;13:117-119.
45 Rimm EB, Ascherio A, Giovannucci E, Spiegelman D, Stampfer MJ, Willett WC. JAMA 1996;275:447-451.

6 Carluccio MA, Siculella L, Ancora MA, Massaro M, Scoditti E, Storelli C, Visioli F, Distante A, De Caterina R. Arterioscler Thromb Vasc Biol 2003;23:622-629.

47 Trichopoulou A, Costacou T, Bamia C, Trichopoulos D. New Engl J Med 2003;348:25992608.

48 Rodriguez Artalejo F, Guallar-Castillon P, Gutierrez-Fisac JL, Ramon Banegas J, del Rey Calero J. Stroke 2003;29:1556-1561.

49 Pearson TA, Blair SN, Daniels SR, Eckel RH, Fair JM, Fortmann SP, Franklin BA, Goldstein LB, Greenland P, Grundy SM, Hong Y, Miller NH, Lauer RM, Ockene IS, Sacco RL, Sallis JF Jr, Smith SC Jr, Stone NJ, Taubert KA. Circulation 2002;106:388-391.

50 Di Castelnuovo A, Iacoviello L, Furman K, Donati MB, de Gaetano G. J.Thromb Haemost 2004, in press.

51 Stampfer MJ, Hu FB, Manson JE, Rimm EB, Willett WC. N Engl J Med. 2000;343:16-22.

52 Hines LM, Stampfer MJ, Ma J, Gaziano JM, Ridker PM, Hankinson SE, Sacks F, Rimm EB, Hunter DJ. N Engl J Med. 2001;344:549-555.

53 de Lorgeril M, Salen P. J. Thromb Haemost 2004 , in press. 